\title{
Measuring Global Competency as the Role of IR
}

\author{
Soichiro Aihara ${ }^{*}$, Hatsuko Yoshikubo *
}

\begin{abstract}
In Japanese higher education, indicators for measuring 21 st century-type competency are in research and development. This study presents the measurements of global competency based on a case study of the Shibaura Institute of Technology as the role of IR. In 2019, we conducted a pilot survey to measure the effects of the study abroad programs on global competency. With further cooperation with co-curricular teams and other colleagues, we would achieve measuring global competency. As Suskie (2014) argues, Institutional Research (IR) can measure competencies on co-curricular activities such as study abroad programs. According to her, there are five advantages of the IR to measure competencies as their role. These are (1) integrate with the mission and policy of the institutions, (2) collect evidence from not only students but also alumni, employers, regional society, (3) form a community across the institutional culture of silos, (4) assess the program with appropriately and systematically, and (5) make the program improvement effectively. This paper aims to identify the positive side of IR in measuring global competency in the Japanese university. Therefore, our research question is what the positive sides are to measuring global competency by the IR. How could IR be measured global competency? In this paper, from the case of a Japanese university, we will show concretely how IR is involved in the measurement of global competency. It is the promotion of joint research projects that produce results in academic conference presentations and academic journals.
\end{abstract}

Keywords: Global Competency, Role of IR, Short-term Study Abroad Program, Top Global University Project

\section{Introduction}

In recent years, diversity awareness is a growing issue among higher educational institutions in Japan and choosing indicators for measuring global competency are becoming more and more important. It is partly because there is a strong demand by Japanese industries which need overseas expansion. It is essential for them to strengthen their overseas operational system to support multi language and diversity functions. In response to the need of industries, the Ministry of Education, Culture, Sports, Science, and Technology (MEXT) launched a financial support plan called Tobitate! (Leap for Tomorrow) to increase the number of Japanese students studying

\footnotetext{
* Shibaura Institute of Technology, Tokyo, Japan
} 
abroad in 2014[1]. Japan Student Services Organization (JASSO) also offers scholarships for the short-term study abroad programs [2].

Based on the JASSO's "Survey of Japanese Students Studying Abroad 2018", the number of students is increasing under the governmental promotion of global human resources development. For example, as Figure 1 shows, 115,146 students studied abroad in 2018, 66\% of which were participants in short-term study abroad programs of less than one month [3].

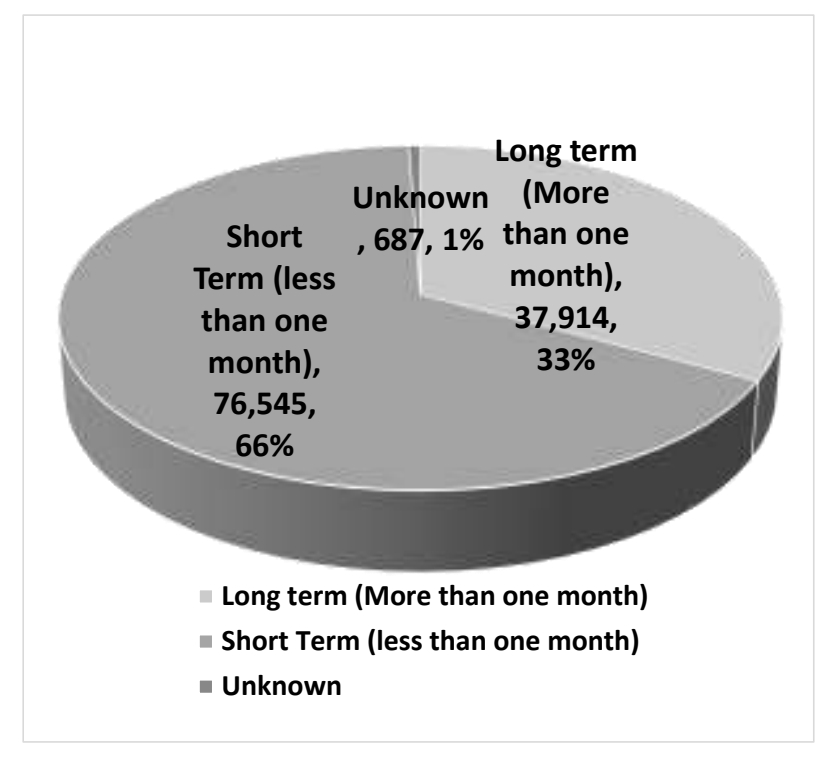

Figure 1: JASSO's "Survey of Japanese Students Studying Abroad 2018"

As the survey shows, the short-term study abroad programs are growing in popularity and essential these days to university education because they can enhance students' linguistic capabilities, improve their cultural knowledge of the host countries, and even transform their world views and opinions without the commitment of months or a year away from home. Therefore, the assessment of the short-term study abroad programs become an important issue to assure educational quality and improve the effectiveness of the programs.

\section{Background}

\subsection{SIT Vision under the Top Global University Project}

In 2014, under the Top Global University Project, 37 universities were chosen as role models for globalization of Japanese higher education. The project's goals are to enhance Japanese universities' international competitiveness and develop global-minded human resources. Shibaura Institute of Technology (SIT) has honorably received the federal fund, and SIT is the only one among private science and engineering universities to be chosen for the project. After being chosen for the project, with a goal of "fostering global engineers and scientists who can learn from the world and contribute to the world", we have decided to devote ourselves to promote improvements in our global education, research activities, and creation of innovation through quality 
assurance and the Plan-Do-Check-Act (PDCA) cycle in accordance with the Washington Accord [4].

We have been dedicating ourselves to promoting this project by focusing on Value Co-Creative Education with four skills below:

(1) Communication skills: ability to understand each other in a global environment, based on broad engineering knowledge and language skills.

(2) Problem finding and solving skills: ability to identify and solve problems with cross-disciplinary thinking and logical skills to determine the social and economic impact of technological development.

(3) Meta-national awareness: ability to think and act from a global perspective, based on national identity and understanding of different cultures.

(4) Technology management skills: ability to manage the social and economic valorization of technological development based on a wide range of knowledge resources. [5]

Basic literacy is an essential skill to be global engineers and scientists. Having a broad range of expertise in all relevant fields as well as English skills for science and technology can be fostered in the lecture and seminar subjects. However, other skills such as meta-national awareness that we expect all students should possess in order to understand the diversity of the international community and to work cooperatively with people from different cultural backgrounds can only be fostered by expanding mobility.

When it comes to diversity, we need actual experiences rather than theoretical arguments, and we need a diversity of experiences to broaden our perspectives. To that end, we are committed to expanding mobility. As for the mobility target for FY2023, we enhance our educational and support systems for study abroad programs which enable all SIT students to have a study abroad experience at least once during their four-year enrollment.

\subsection{Study Abroad Program at SIT}

Study Abroad Programs at SIT

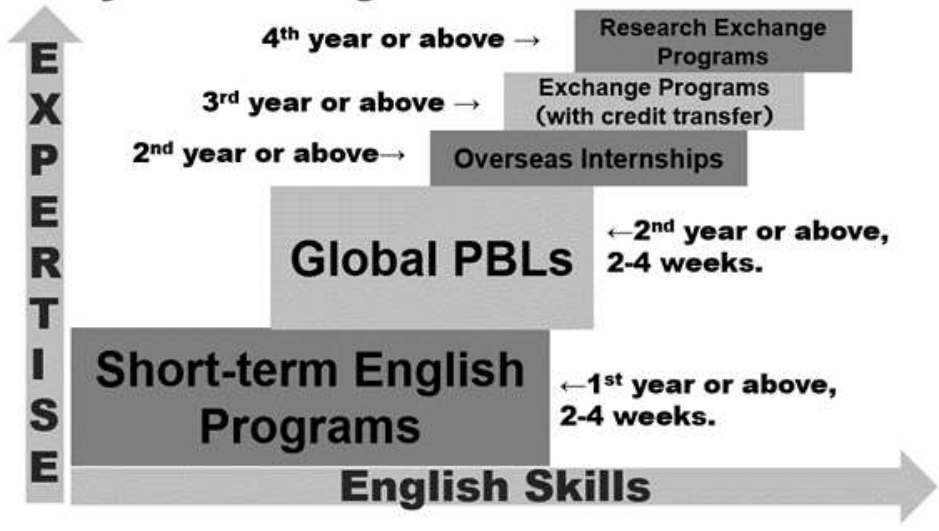

Figure 2: Study Abroad Programs at SIT 
In order to attain our objective, we have been expanding the number of study abroad programs. Division of Global Initiatives is operating study abroad programs in coordinating programs between partner universities. Figure 2 demonstrates that we provide five types of study abroad programs with the aim of expanding mobility. First, we encourage first-year students to participate in English training programs to overcome their weaknesses in English. Secondly, we recommend second-year and third-year students participate in Global PBL programs. After experiencing English training programs and Global PBL programs, a certain number of students willingly move on to the next steps, to the long-term study abroad programs, such as overseas internships, exchange programs with credit transfer, and research exchange programs. The feature of each program is described in the following pages.

\subsubsection{Short-term English Programs}

It is a language training program that takes place over summer and spring breaks in about two weeks to a month. Although the curriculum is structured around English lessons, the program also includes customized activities for engineering students, such as exchanges with local students, field trips to laboratories and factories, and cultural experiences, in addition to brushing up English. The program structure allows students to cultivate diverse values while being exposed to culture. Credits can be earned from all the short-term English programs and will be counted as transfer credit upon their return.

\subsubsection{Global PBLs}

Project-based learning is a pedagogical method in which students learn by actively engaging in the projects and they are instructed to find a solution and present their outcomes. According to Bender (2012), it is recognized that Dewey was one of the early advocates for the Project-based learning (PBL) [6]. The methodology of PBL can be well adopted into our educational frameworks since we aim to foster engineers capable of playing pivotal roles on the global stage. In the process of expanding our study abroad programs, we have developed the PBL methodology as one of featuring study abroad programs called Global PBL (hereafter, we refer to it as gPBL).

Our gPBL programs have been implemented as one of the methods for constructing the "Global Science and Engineering Human Resources Development Model" of SIT. We define gPBLs as joint international programs between SIT students and students from our partner universities. It is one of our unique approaches that SIT provides for students to have technical discussion experience on a research project with students from overseas partner universities and to improve their communication skills in English through the workshop. In gPBLs, students are sent to partner universities abroad to form international teams and work on engineering issues in collaboration with other students. This lasts for two to four weeks. As of FY2019, gPBLs are offered in all 16 departments at SIT. Credits can be earned from the vast majority of gPBLs and will be counted as transfer credits upon their return.

A basic procedure for gPBLs is illustrated in Figure 3. The contents of the programs vary from cross-disciplinary, company-cooperative, large-scale programs involving multiple universities inside and outside of Japan, to programs that combine language and specialized fields. In each distinctive program, students can develop practical problem-solving skills in their field, while simultaneously learning about the differences in foreign cultures, customs and ways of thinking to become a global engineer. We have also implemented in-house gPBLs at SIT which invite participants from abroad [7]. 


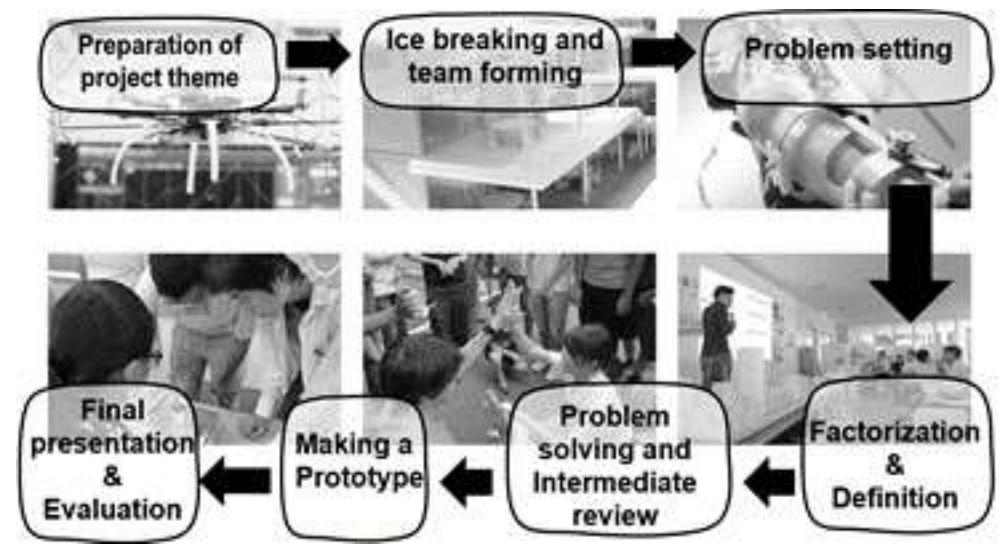

Figre 3: A Basic Procedure for gPBLs

\subsubsection{Overseas Internship Programs}

This program provides work experience at corporate locations abroad (research and development sites, manufacturing sites, offices, etc.). The program is open to students in the second year or above and designed for students with intermediate or advanced levels of English proficiency and expertise in their majoring fields. Most of the overseas internship programs are offered during the summer vacation for two to four weeks. Through the internship programs, students can understand the diversity of cultures, ways of thinking and develop their ability to see things from multiple perspectives. In addition, the program provides students with an opportunity to interact with Japanese staff and managers who are working for their overseas operation offices, which might help them build their future career. When it comes to choosing the participants, we emphasize on careful and meticulous matching to increase the satisfaction of both students and companies.

\subsubsection{Exchange Programs with Credit Transfer}

This is a program that allows students to take courses offered in English at our partner universities. Most of the courses are specialized. In principle, students must be in their third year or above at the time of departure and will study abroad for one or two semesters, depending on the academic calendar of the partner university [8].

\subsubsection{Research Exchange Programs}

In the research exchange programs, students are assigned to a laboratory at the partner university and conduct research activities in line with their own research themes. Unlike the coursework type, this program is not tied to the academic calendar, so the schedule can be arranged freely if the supervisor and other parties concerned, including the partner university's academic advisor, agree to the trip. In principle, the program is open to 4 th year undergraduate students or above at the time of departure, and the duration of studying abroad can be arranged from two weeks up to one year.

\subsection{Result 1 (Number of Dispatched Students)}

As a result of promoting activities toward the goal of "all students have at least one overseas experience while their enrollment at undergraduate programs," the number of dispatched students 
has, as shown in Figure 4, increased from 172 at the end of the FY2012 to 1,586 at the end of the FY 2019. That is an increase of 1,414 people in 7 years, 9 times more than the FY 2012.

Of these, however, as seen in Figure 5, 85\% (1,358 students) are participants in the short-term study abroad programs of less than one month. And $46 \%$ of the short-term program participants (734 students) are the participants of the overseas English training programs while 39\% (624 students) are of the gPBLs [9].

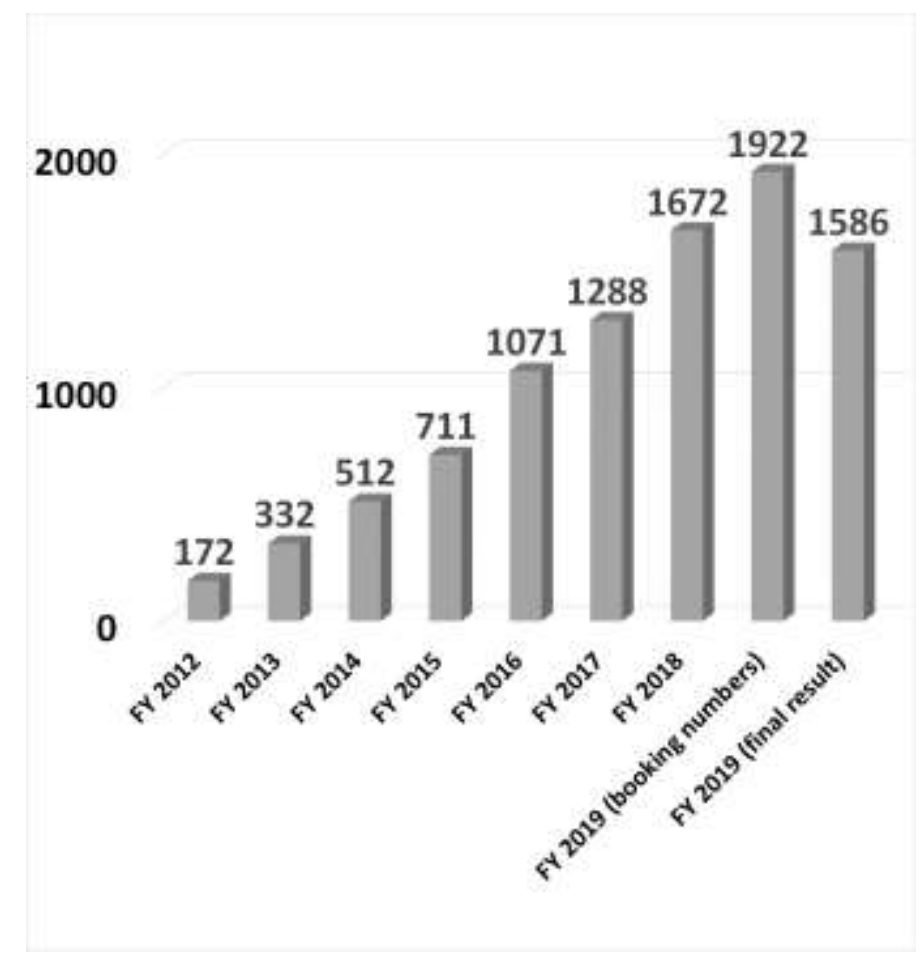

Figure 4: The Changes in Number of Dispatched Students (2012-2019)

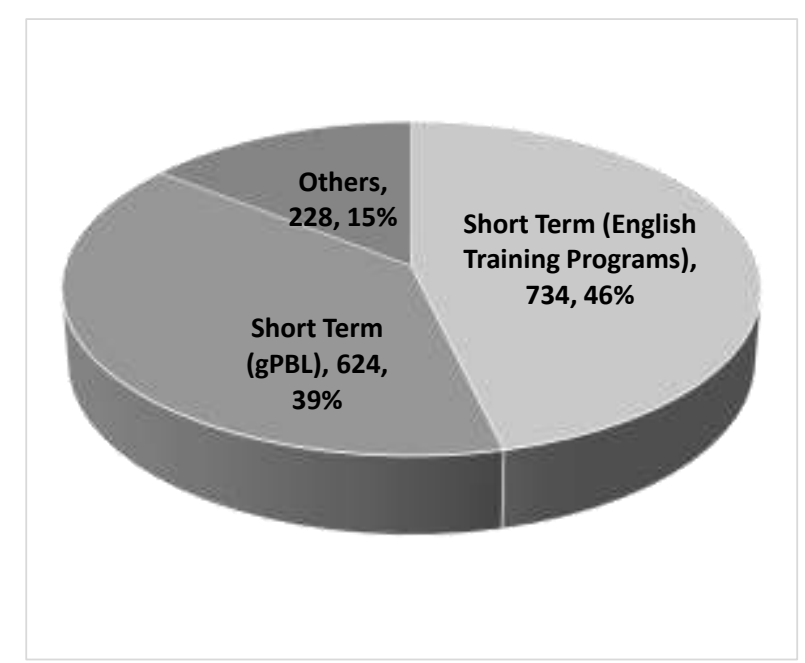

Figure 5: Number of Participants by Program Type in FY2019 
As Table 1 describes, in comparison with other universities, SIT ranks the fifth in Japan in terms of the number of dispatched students overseas under agreements between partner universities [10].

Since many participants receive scholarship to participate in the study abroad pro-grams, it is necessary to measure the effectiveness of the programs and verify its quality assurance, in addition to increasing the number of students, from the perspective of accountability to the funding source. In this way, it became an essential issue for SIT to verify the effects of the short-term study abroad programs.

Table 1: University Ranking by Number of Dispatched Students under partnership agreements and other exchanges in FY 2018

\begin{tabular}{|c|l|r|}
\hline Ranking & \multicolumn{1}{|c|}{ Name of University } & No. of Dispatched Students \\
\hline 1 & Kansai Gakuin Daigaku & 1,833 \\
\hline 2 & Kansai Gaidai University & 1,659 \\
\hline 3 & Waseda University & 1,656 \\
\hline 4 & Ritumeikan University & 1,548 \\
\hline 5 & Shibaura Institute of Technology & 1,364 \\
\hline 6 & Meiji University & 1,055 \\
\hline 7 & Rikkyo University & 1,016 \\
\hline 8 & Toyo University & 895 \\
\hline 9 & Dosisha University & 872 \\
\hline 10 & Tokyo University & 855 \\
\hline
\end{tabular}

\subsection{Result 2 (CEFR)}

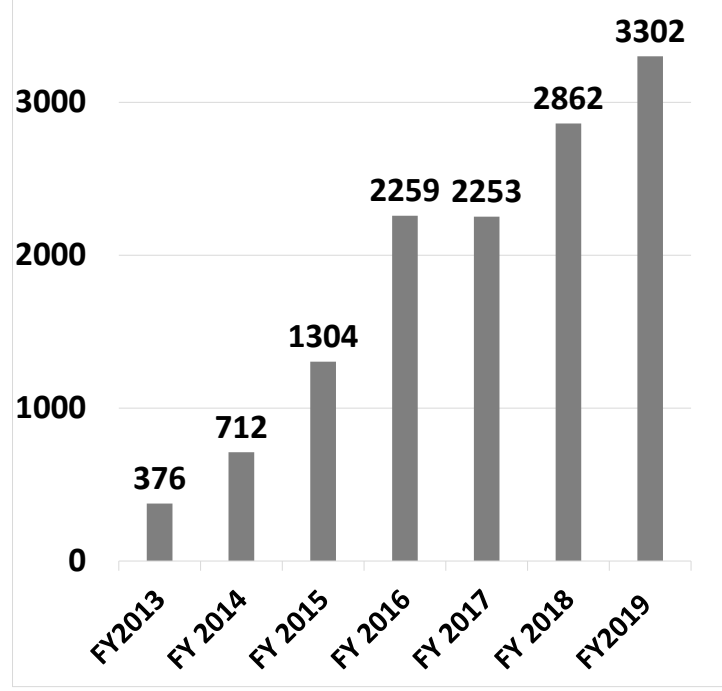

Figure 6: Number of Students Reaching CEFR B1 Level

Studying abroad is often seen as the best tool to improve students' language skills. Several researchers such as Suzuki \& Chiba (2017) and Kimura (2012) have reported that students would increase their linguistic skills and tend to be more motivated to learn after their study abroad 
experience [11][12]. However, that research is usually based on a small number of samples and self-reports by students. Thus, SIT has been conducting all students survey on how their Common European Framework of Reference for Languages (CEFR) level in English, has improved in the process of developing our study abroad programs. As a result, as represented in Figure 6, the number of students with CEFR B1 level or more has greatly improved from 376 at the end of FY 2013 to 3302 at the end of FY 2019 which is an increase of 7-fold compared with FY 2013[13].

However, in addition to improving language skills, global competency is also necessary to be a global engineer to understand the diversity of the international community and to work collaboratively with people from different cultural backgrounds.

\section{Global Competency and the Role of IR}

\subsection{Status of Definition and Measurement of Global Competency}

The current status of definition and measurement of global competency is as follows. Ninomiya (2018) analyzed design papers of projects that are the Go Global Japan (GGJ) and the Super Global University (SGU). In university education, he made clear that the definition of global competency varies widely among universities [14]. In the secondary education field, Murase and Akita (2017) have developed a questionnaire to measure global competency relying on the OECD framework [15]. As for the higher education field, Sato and Sakamoto (2020) developed a self-authorship questionnaire to develop 21st-century competencies [16]. The Japan Association for Global Competency Education is also developing a questionnaire for measuring Crosscultural competency [17]. However, regarding science and engineering education in Japan, Yamada (2017) pointed that "there is almost no research focusing on the STEM higher education and the 21st-century type of liberal education and skills, especially interdisciplinary and crosscultural understanding" [18]. She refers to "STEM" higher education as the collective term for the "science, technology, engineering, and mathematics" education. Thus, in Japanese higher education, the indicators of global competency are currently in the development stage. However, at overseas universities, various indicators are measuring global competency. And they have used these indicators to assure the quality of university education.

MGUDS-S is an index developed in 2000 to measure global competency [19]. Today it is widely used in overseas universities. SIT has engaged in developing the indicator on global competency in science and engineering education. Then we created a Japanese version of the MivilleGuzman Universality-Diversity Scale, Short Form (MGUDS-S), which has developed at American higher education [20]. Oda has developed a Japanese version of MGUD-S that takes into consideration the differences in culture and society between Japan and the United States [21]. MGUDS-S measures global competencies with the Universal-Diverse Orientation(UDO). UDO is "an attitude of awareness and acceptance of both similarities and differences that exist among people." MGUDS has three subscales, each measuring UDO in terms of behavior, recognition, and emotion. The value of this UDO is the global competency [22]. The number of items in the short-form version is 15; thus, the respondents' burden is negligible. It can be used free of charge with the permission of the author. The focus of this study is not the examination of MGUDS-S as an indicator of global competency. Therefore, this paper does not discuss the meaning of the statistical significance, subscales, and items. 


\subsection{The Role of IR}

The Japanese Association of Higher Education Research journal featured IR by their 19th volume of "Higher Education Research." Asano (2016) cites IR as the data broker in database construction [23]. Besides, Otawa (2016) proposed the "role of spreading the culture of formative problem understanding within the university" after additionally modifying the I-E-O model [24]. However, they do not mention the role of IR based on the case of measuring global competency. It might be a fair view because many faculty members think that departments in charge of international education programs, such as the International Student Center, measure global competency. Besides, faculty members who belong to such departments and in charge of those programs might measure the global competency to assess the educational effect. Is it the role of IR to measure global competency? What are the positive sides to measuring global competency by the IR? These are also the research questions of this paper.

Suskie (2014) explored measuring global competencies and IR's role in assessing co-curricular learning activities such as study abroad programs [25]. According to her, "co-curricular learning experiences" are "that help students achieve meaningful learning outcomes in concert with academic study (p.6)." Some examples of co-curricular learning experiences include "service-learning experiences, internships, study abroad, undergraduate research, and living-learning communities (p.28)." These learning experiences are also known as highimpact practices (HIPs) that significantly affect student engagement, retention, and learning [26].

She argues that IR can collaborate with co-curricular teams:

1. To integrate the learning outcomes of the co-curricular activities with the mission and policies of the university

2. To collect evidence from not only students but also alumni, employers, and local communities

3. To form a community across the institutional culture of silos

4. To assess the program appropriately and systematically

5. To make the program improvement effectively

First, to integrate the learning outcomes of the co-curricular activities with the university's mission and policies, she said co-curricular experiences often have goals that are particularly difficult to articulate clearly. Furthermore, she said co-curricular experiences are that their learning outcomes do not always align with the institutional mission, goals, and /or student learning outcomes (p.7). However, she argues that IR members who have experience assessing either student learning or institutional effectiveness can help co-curricular teams articulate and focus on a few clear, relevant learning outcomes that integrate well with institutional mission and goals (p.8). Co-curricular teams have a keen interest in individual study abroad programs. It is the same as academic professions having a strong identity in their fields in university organizations. For Co-curricular teams, measuring global competencies aims to improve study abroad programs. Therefore, it will be the role of IR to bridge the missions and policies of the university with the Co-curricular teams in measuring global competencies. Then, to construct the bridge, we need "the culture of formative problem understanding," Otawa (2016) says [24]. 
Second, to collect evidence from students and alumni, employers, and local communities, she said there is a culture of reticence in colleges and universities that they do not communicate to stakeholders the impact of co-curricular experiences. She argues, however, that IR members can help co-curricular teams collect and use external and internal evidence - from employers, the community, and alumni (p.8). IR is what Asano (2016) calls a "data broker" [23]. IR surveys not only students and faculty members, but also graduates and employers. Student surveys can analyze study abroad programs from the overall experience of university education. IRs can also get evaluations of study abroad programs from graduates and employers. Both are too heavy jobs for Co-curricular teams alone.

Third, as to form a community across the institutional culture of silos, she picks up one example that there are the different terms but the same meaning. The term of "student learning" in academic programs but "student development" in co-curricular experiences, when in fact, both learning and development take place in both settings (p.9). However, she argues that IR members are often skilled at seeing the big picture and how the pieces of institutional operations fit together (p.10). As IR is a cross-organization, adding statistical figures to a common language enables communication between university organizations with different terms. And it becomes possible to form "the culture of formative problem understanding."

Fourth, to assess the program appropriately and systematically, she said that co-curricular teams sometimes lack the expertise and mindset to seek systematic evidence. Assessing competencies such as teamwork, organizational skills, spiritual development, and lifelong commitment to serving others is difficult and time-consuming than assessing, such as writing or quantitative skills. However, she argues that IR can help co-curricular teams learn about and use acceptable assessment practices (p.11). IR handles various assessments for students, faculty, graduates, employers, etc. as a "data broker". Therefore, the involvement of IR enables an appropriately and systematically assessment.

Fifth, to make the program improve effectively, she said that some co-curricular experiences operate in an institutional culture of antecedents and anecdotes rather than systematic reviews. She argues three points as the role of IR:

1. Summarize and share the data in ways that help identify areas for improvement.

2. Build an evidence-based case for co-curricular programs by helping institutional leaders see the impacts, benefits, and needs of those programs.

3. Ensure the continued viability of co-curricular programs (p.11).

\section{A Case Study of SIT}

At the SIT, to develop global human resources for science and engineering, co-curricular teams and staff of the International Division have measured communication operational proficiency by using the CEFR and the TOEIC® L \& R score. They also have measured problem-solving ability with the rubric of the global PBL and the PROG test. PROG means "a progress report on generic skills." This test is an assessment test that supports the growth of generic skills widely used in Japanese universities. However, regarding the development of global competencies, student satisfaction and self-report are dominant indicators. A more objective tool for measuring global competency, such as meta-national awareness, is requiring. They have needed to reinforce with sophisticated, more objective indicators. 


\subsection{Student Survey of the University IR Consortium}

Our Institution has participated in the Universities Institutional Research Consortium since 2017. It enables us to collect the data systematically from student engagement survey. Using their student survey data, IR measured the global competency. IR is in charge of national standard student engagement surveys. On the other hand, co-curricular teams manage study abroad programs. They are familiar with the programs. If both officers form a partnership, the engagement of program participants can be measure from surveys. Thus, IR and co-curricular teams made a collaborative presentation at the forum, such as the 41 st annual conference of the Japan Association for College and University Education (2019) [27].

Fig. 7 is that from the 2017 student engagement survey (3rd grade), regarding "competency to cooperate with people of different races and cultures(Q10-I)", compare 192 participants of four short-term study abroad programs (black bar) with 1,357 non-participants (white bar). It shows that the share of students who answered that their competencies have "much stronger" or "stronger" is $76 \%(18 \%+58 \%)$ of program participants, while $47 \%(9 \%$ $+38 \%$ ) of non-participants. Students who answered their competencies have increased is much more among the participants. The results of this study revealed the effectiveness of the program university-wide concerning global competencies by benchmarking. It clarified the path that bridges the university's mission and policies in measuring the effectiveness of study abroad programs. Furthermore, it showed the applicability to alumni surveys and employer surveys.

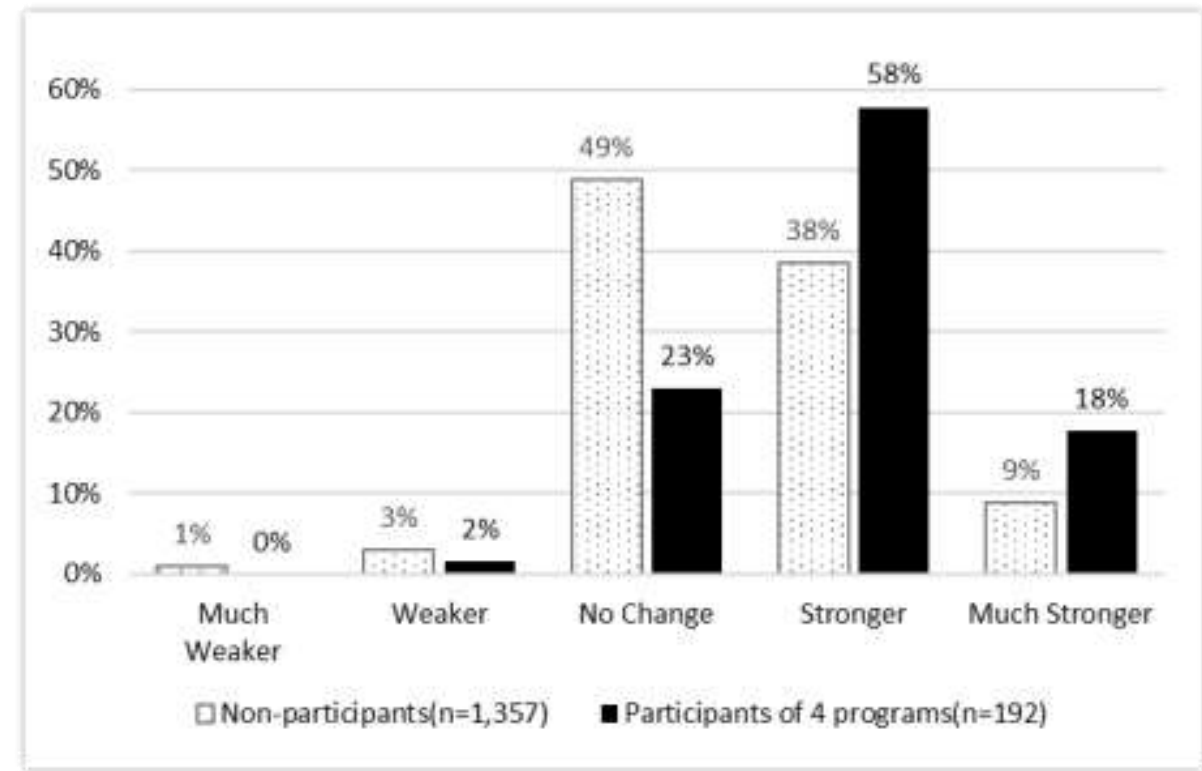

Figure 7: Competency to Cooperate with People of Different Races/Cultures【Q10-I】 Student Engagement Survey 2017 (3rd grade)

Source: Yoshikubo, Aihara, Tachibara [27]

IR can realize the five advantages that Suskie pointed out by cooperating with the cocurricular teams using the student engagement survey. This survey has conducted on a standardized questionnaire over the institutions. The survey results are scrutinized under the colleges and universities' mission and policy and feedback to not only the colleges and 
universities but also open to the public. The survey items are the same as the other universities and could be the same for alumni and communities' surveys. It could be benchmarking not only with universities in Japan but also in the United States. Benchmarking should be done so that the program would improve effectively. Therefore, effective improvement with the support of the university executive officers is also possible. And most importantly, without IR and co-curricular teams cooperating, study abroad programs cannot be assessed with student surveys.

The student survey, however, is self-reported by the student. There are criticisms that the result is lacking in objectivity. There is also criticism about the selection bias of respondents. The assessment of competencies with single-item has insufficient evidence. Thus, we decided to use a specialized questionnaire.

\subsection{The MGUDS-S Japanese version}

While many tools objectively measure the effects of study abroad programs, such as Beliefs, Events, and Values Inventory (BEVI) (Nishitani 2018), these require measuring global competency using a questionnaire to consider international assessment results [28]. We conducted a pilot survey of participants in the short-term study abroad programs using the Japanese version of MGUDS-S translated by Oda (2019) [21]. Then, IR and co-curricular teams made a presentation at the 7th National Convention of the Japan Association for Global Competency Education (2019) [29]. Again, without the cooperation of IR and co-curricular teams, collaborative presentation was impossible. IR has the ability to research and analyze the data statistically. The cocurricular teams have experienced management of study abroad programs, and they have knowledge about assessments tool of study abroad programs.

Table 2: An Assessment of Global Competency by the MGUDS-S

\begin{tabular}{lcccccccc}
\hline & \multicolumn{3}{c}{ Pre-test } & \multicolumn{2}{c}{ Post-test } & \multirow{2}{*}{ Change } & \multirow{2}{*}{ t-value } & $\mathrm{d}$ \\
\cline { 2 - 8 } & mean & SD & mean & SD & & & \\
\hline Diversity of Contact:DC & 21.50 & 4.59 & 23.41 & 4.09 & 1.91 & $10.76^{* * *}$ & .44 \\
\hline Relativistic Appreciation:RA & 23.69 & 3.54 & 24.51 & 3.84 & .82 & $4.75^{* * *}$ & .22 \\
\hline Comfort with Differences:CD & 16.24 & 5.09 & 17.23 & 5.80 & .99 & $4.18^{* * *}$ & .18 \\
\hline MGUDS-S Total Score & 61.43 & 7.95 & 65.16 & 8.26 & 3.73 & $11.07 * * *$ & .46 \\
\hline
\end{tabular}

Source: The 2019 MGUDS-S Pilot Survey of the Shibaura Institute of Technology. $n=281$, $* * * \mathrm{p}<.001$.

Table 2 is the pre-survey and post-survey results of 281 participants who participated in the shortterm study abroad programs from the 2019 MGUDS-S Japanese version of the trial survey. MGUDS-S measures global competency on three subscales and total scale. Then, the value of UDO, that is, Universal-Diverse Orientation, is set to global competency. Comparing the prevalues and post-values, the average value of Diversity of Contact: DC, which measures UDO from the behavioral aspect, has increased from 21.50 to 23.41. Relativistic Appreciation: RA, which measures UDO from the recognition aspect, has increased from 23.69 to 24.51. Comfort with Difference, which measures UDO from the emotional aspect, has increased from 16.24 to 17.23. Finally, the total score of MGUDS-S, which is the sum of the three scales, has increased from 61.43 to 65.16 . All of these increases are statistically significant at the $0.1 \%$ level. Regarding the effect size, the total score of MGUDS-S and Diversity of Contact: DC is medium, the effect size of Relativistic Appreciation: RA and Comfort with Difference are small. Although not shown 
in the table, a similar result was obtained in university surveys in America. With the introduction of MGUDS-S, we could measure global competency more objectively and internationally acceptable from the single item measurement of the student engagement survey. That means the program can become assessed with more scrutiny and indicate improvement with three subscales.

In 2020, we plan to incorporate the MGUDS-S Japanese version into the student engagement survey and conduct it for all students to respond to the criticism of respondent bias. IR members can implement these surveys in cooperation with not only the co-curricular teams but also officers of Faculty Development (FD) and Staff Development (SD) and other colleagues.

\section{Discussion and Further Study}

At the SIT, IR office belong to a cross-sectoral organization named the Center for Educational Innovation Promotion. This organization setting is also facilitating collaborations across the boundaries of academic silos. The collaboration between IR members and cocurricular teams can realize the five points which Suskie argues. First, IR can integrate the survey of study abroad programs into university-wide student surveys. That will be bridge measurements of the program with university missions and policies. Second, by applying it not only to student surveys but also to alumni surveys and employer surveys, evidence can be widely collected. Third, collaboration among university organizations forms a community that transcends the university's silos culture. The results will reflect in joint presentations at academic conferences, reports, and papers. Fourth, IR has the ability to analyze data statistically. They know well about measuring and analyzing data. On the other hand, co-curricular teams have deep knowledge of study abroad programs. They know well about evaluating the program content and communication proficiency. It is necessary to assess global competency by utilizing each characteristic and collaborating. Through collaboration between the two, appropriate and systematic assessment can perform. Fifth, IR presents points to improve from the data. For example, in a student survey, benchmarking is used. It, with the support of university executives, leads to effective improvement of study abroad programs. However, since the case study on SIT is at the phase of the pilot survey, this fifth point is a future issue for the role of IR. Thus, the five advantages which Suskie argued became possible for measuring the global competency. It seems crucial to collaborate with colleagues regarding the program's improvement in spreading the culture of evidence-based formative understanding.

The five points Suskie discussed find to be feasible from the SIT case study. However, she does not give examples about university-wide student surveys, benchmarking, or joint presentations at academic conferences. These are examples of how IR works with co-curricular teams. The case study has revealed these examples.

\section{Acknowledgement}

The authors sincerely thank the co-researchers of this project and the staff of the Center of Promotion of Educational Innovation and Division of Global Initiatives of Shibaura Institute of Technology for their contribution to this project and for the permission to use the data. This research is supported by JSPS Grans-in-Aid for Scientific Research: JP18K02735 and JP 20 K02947. 


\section{References}

[1] "Tobitate!" scholarships can be referred to the following site: https://tobitate.mext.go.jp/program/index.html (reference Nov. 20, 2020)

[2] JASSO's scholarships for the short-term study abroad programs can be referred to the following site: https://www.jasso.go.jp/ryugaku/study_a/scholarship/haken/index.html (reference Nov. 20, 2020)

[3] The pie chart in Figure 1 was created by author based on the data from JASSO's "Survey of Japanese Students Studying Abroad 2018" which can be referred to the following site: https://www.studyinjapan.go.jp/ja/_mt/2020/08/date2018n.pdf(reference Nov. 20, 2020)

[4] Washington Accord; https://www.ieagreements.org/accords/washington/

[5] SIT Annual Report 2019 - Top Global University Project -, Shibaura Institute of Technology, August, 2020, pp.5; https://www.shibaura-it.ac.jp/global/summary/project/sgu_plan.html (reference Nov. 20, 2020)

[6] W. N. Bender, Project-Based Learning: Differentiating Instruction for the $21^{\text {st }}$ Century, Corwin, 2012, p.42.

[7] The report of gPBL at SIT can be referred to the following site: https://www.shibaurait.ac.jp/global/dispatch/program/global_pbl/program_2019.html (reference Nov. 20, 2020)

[8] List of partner universities can be referred to the following site: https://www.shibaurait.ac.jp/albums/abm.php?d=466\&f=abm00012326.pdf\&n=StudentExchange_Undergraduate_CoursetakingList20201105.pdf (reference Nov. 20, 2020)

[9] The bar graph in figure 4 "Changes in Number of Dispatched Students (2012-2019)" was created by author based on the data obtained from the following site: https://www.shibaurait.ac.jp/global/summary/data/\#dispatch (reference Nov. 20, 2020)

[10] Table 1 was created by author based on the data from JASSO's "Survey of Japanese Students Studying Abroad 2018" which can be referred to the following site: https:/www.studyinjapan.go.jp/ja/_mt/2020/08/date2018n.pdf(reference Nov. 20, 2020)

[11] R. Suzuki, C. Hayashi, "A Study on the Lasting Effects of a Short-term Study Abroad Program on Students' English Proficiency and Affective Variables," KATE Journal, vol.31, 2017, pp.14-28.

[12] K. Kimura, "Changes of Writing Fluency and the Affective Factors Behind Them - In the Case of the Short-term Overseas Program Participants-", KATE Journal, vol. 26, 2012, pp.5365.

[13] The bar graph in figure 6 was created by author based on the follow-up data submitted to MEXT for the Top Global Project which can be referred to the following site: https://www.jsps.go.jp/j-sgu/follow-up.html (reference Nov. 20, 2020) 
[14] A. Ninomiya, "How are global human resources and the (Global) Competency Designed?: an analysis of the Programs of GGJ, SGU, Inter-University Exchange Projects and SGH" Web magazine Study Abroad Exchange, vol.82,pp.1-12, 2018.

[15] M. Murase and K. Akita, "Pilot study report on the development of global competencies through project-based learning: a self-assessment survey of students," Bulletin of the Graduate School of Education, the University of Tokyo, vol.57, pp.261-270, 2017.

[16] F. Sato and A. Sakamoto, " Development, Reliability, and Validity of a Japanese SelfAuthorship Scale (JSAS)", Journal of Japan Association for College and University Education, vol.41, no.2, pp.25-34, 2020.

[17] T. Kudo and T. Aoyagi, "Developing a measurement scale for assessment of intercultural communicative competence", Journal of the Japan Association for Global Competency Education, vol.7, no.1, pp.30-35, 2019.

[18] R. Yamada, "How does STEM higher education integrate the 21 century learning outcomes? : global competences and challenges of STEM higher education," Journal of Japan Association for College and University Education, vol.39, no.1, pp.86-90, 2017.

[19] J. N. Fuertes, M. L. Miville, J. J. Mohr, W. E. Sedlacek, and D. Gretchen, "Factor structure and short-form of the miville-guzman universality-diversity scale," Measurement and Evaluation in Counseling and Development, vol.33, no.3, pp.157-169, 2000. DOI:10.1080/ 07481756.2000.12069007

[20] S. Oda, A. K. Yamazaki and M. Inoue,"Review of previous research and Japan-US Ccmparative study of global competency in engineering," Journal of the Japan Association for Global Competency Education, vol. 6, no. 1, pp.11-12, 2018.

[21] S. Oda, Doctoral Dissertation, Development and Evaluation of Global Competency for Science and Engineering Personnel, Shibaura Institute of Technology, Kou, no. 246, 2019.

[22] M. L.Miville, P. Holloway, C. Gelso, R. Pannu, et al., "Appreciating Similarities and Valuing Differences: The Miville-Guzman Universality-Diversity Scale, "Journal of Counseling Psychology, vol.46, no.3, pp.291-307, 1999.

[23] S. Asano, "The development of an IR database:issues and challenges facing Japanese universities," Japanese Journal of Higher Education Research, vol.19, pp.49-66, 2016.

[24] N. Otawa,"How can a student survey be utilized to promote university reform?:a fresh example of student surveys and IR," Japanese Journal of Higher Education Research, vol.19, pp.87-106, 2016.

[25] L. Suskie, "Introduction to measuring co-curricular learning," New Directions for Institutional Research, no.164, pp.5-13, 2014.

[26] G. D. Kuh, High-impact Educational Practices: What they are, who has access to them, and why they matter. Washington, DC: Association of American Colleges \& Universities, 32p., 2008. 
[27] H.Yoshikubo, S.Aihara, M.Tachibana,"An assessment of short-term language training programs at engineering university," 41st Annual Conference Summary, Japan Association for College and University Education, pp.98-99.

[28] H. Nishitani, "Objective measurement of study abroad experience: Using BEVI (Subtopic: Efforts to measure the effect of study abroad experience: Focusing on overseas short-term dispatch programs)," University Current Review vol.67, no.380, pp.74-79, 2018 .

[29] S. Aihara, H. Yoshikubo, S. Oda, M. Tachibana, A. Yamazaki, M. Inoue, "An assessment of global competency at the Shibaura Institute of Technology: a report of MGUDS-S trial survey 2019, "7th Annual Conference Summary, Japan Association for Global Competency Education, pp.22-23. 